\title{
Product portfolio management - Targets and key performance indicators for product portfolio renewal over life cycle
}

Arto Tolonen, Marzieh Shahmarichatghieh, Janne Harkonen, Harri Haapasalo

Industrial Engineering and Management, University of Oulu, P.O. Box 4610, FI90014 Oulu, Finland

\begin{abstract}
The main purpose of this study is to widen the scope of product portfolio management (PPM) targets and key performance indicators (KPIs) to cover all phases of the product life cycle. Earlier research mainly covers PPM performance management within new product development (NPD) life cycle only. In addition, current challenges relating to PPM performance management over product life cycle are studied.

The research method includes current state analysis based on both a thorough literature review and analysing ten case companies that represent hardware (HW), software (SW), services and solutions type businesses. The contribution is discussed and validated by a focus group consisting of all the case companies before making final conclusions.

The principal results of this study include the potential framework for managing product portfolio renewal over the entire product life cycle based on strategic, tactical and operational performance measures. The PPM performance management, its business impact and connection to business processes and performance management dashboard are discussed.

The role of PPM as a means of executive level dynamic performance management and decision-making sets further questions for researchers for systematic product portfolio definitions, governance models, processes and tools over product life cycle.
\end{abstract}

Keywords: Product portfolio management Performance management Dynamic decision-making Product life cycle management

Arto Tolonen, Marzieh Shahmarichatghieh, Janne Harkonen, Harri Haapasalo, Product portfolio management Targets and key performance indicators for product portfolio renewal over life cycle, 


\section{Introduction}

Product portfolio renewal is about adding new products to the product portfolio, enhancing and modifying the existing products and removing obsolete ones. New products are seen vital for securing a company's competitive position in the market (e.g. Balachandra, 1997; Poolton and Barclay, 1998; Lynn et al., 1999). Nevertheless, the share of totally new product development is decreasing (Barczak et al., 2009) while the existing products are upgraded frequently to achieve cost reductions and functional improvements (Hänninen et al., 2013). Company mergers and acquisitions may also widen a company's product portfolio with- out conducting new product development. This type of situations leads easily to widening product portfolios as has occurred in several industries during the recent decades (e.g. den Hartog, 2012). In fact, according to Droge et al. (2012) for every obsolete product removed from the portfolio, 1.8 new products are added.

The common belief is that a diverse product portfolio will have a positive effect on a company's sales volumes, and the product variety is often justified by fulfilling customers' requirements (Wan et al., 2012). Product variety has emerged as a source of competitive differentiation in response to requests for increasingly customised products and services (Hayes et al., 2005). However, too wide product range can lead to mass confusion by the customers, thus weakening sales (Wan et al., 2012). In fact, internal product variety and complexity usually reduce sales per product variant (Cooper and Griffiths, 1994; Randall and Ulrich, 2001; Thonemann and Bradley, 2002; Wan et al., 2012). According to Orfi et al. (2011) the product variety leads to product complexity with negative impacts on productivity, costs, new product development time, and customer satisfaction. Simultaneously offering functional products and new innovative products is also seen to complicate the demand supply chain (Langenberg et al., 2012). According to Gunasekaran et al. (2004) a wide range of products decreases the performance of the operational supply chain, resulting in less value added per headcount, longer lead times, and decrease in on time deliveries.

Today, companies are often too focused on managing single products instead of managing the entire product range. Consequently, companies could benefit from considering several product families rather than separately optimising each product (Salvador et al., 2002).

Productivity can be achieved by working smarter according to company strategic objectives rather than just increasing the amount of work (Pekuri et al., 2011). One aspect that is often ignored in the literature is managing the product plans, products under development, and products in the market over the product life cycles, from an end-to-end viewpoint. The new and existing products require different types of target setting and key performance indicators (O'Reilly and Tushman, 2004). According to a new product development (NPD) benchmarking study (Cooper et al., 2004) there is a correlation between the success of the business results and systematic use of product portfolio management (PPM) targets and key performance indicators (KPIs). The best performing companies use PPM targets and KPIs more frequently and systematically, to analyse and adjust their NPD phase of the product portfolio. According to Griffin (1997), about one third of the sales come from technologies and products introduced five years ago, hence, products being introduced today will impact future sales revenue in a similar way. Based on O'Reilly and Tushman (2004), successful product portfolio management requires constant incremental innovations and also architectural 
innovations. Existing products can be further developed by smaller incremental innovations to extend their life cycle, improve cost competitiveness and create additional value to customers. Fundamental changes in technologies and business models require architectural innovations. Discontinuous innovations are required as well to make the oldest technology and products obsolete (O'Reilly and Tushman, 2004). Analysing product complexity is an additional product portfolio viewpoint. Orfi et al. (2011) defines five dimensions of product complexity: design, development, manufacturing and assembly, and supply chain. Each of these dimensions has impact to the direct and indirect product costs.

This research paper aims to analyse and improve the PPM target setting and performance management approach especially over the entire product life cycle to contribute to existing literature and to overcome the current PPM challenges faced by the case companies of this study. Based on the findings, a new framework is proposed for PPM performance management over life cycle. The above discussion can be condensed into the following research questions (RQs):

RQ1. What are the PPM targets and KPIs over life cycle? RQ2. What are the current PPM challenges, PPM targets and KPIs in case companies?

RQ3: What kind of performance management framework would promote product portfolio renewal?

This study addresses the research questions by using a qualitative and inductive approach, through case company interviews and a literature review. RQ1 is answered in Chapter 2 by reviewing the literature and earlier research on strategic performance management for PPM. RQ2 and RQ3 are answered in Chapter 4 by analysing ten case companies and developing and validating the new proposed framework for PPM. 


\section{Literature review}

Product portfolio can consist of hardware (HW), software (SW), Services and Documentation types of products, which are connected to higher and lower level groups and items. The products in a portfolio can be classified in many ways; by customer segments, by technology generations, by product families, etc. (Kropsu-Vehkapera and Haapasalo, 2011). The share of totally new product development is decreasing which is seen as a drop of business performance (Barczak et al., 2009). Cooper et al. (2004) conducted a benchmarking study on "best-in-class" innovation strategy and related impact on business performance. High performers were seen to have more focus on innovation and technology strategy, which lead to more innovative NPD projects to create new products. $75 \%$ of successful product ideas are seen come from the marketplace (Cooper, 1996). According to Cooper et al. (2004) the best performing companies direct $40 \%$ of their product development capabilities for totally new products and innovations. The worst performing companies use less than $1 / 3$ of their capabilities for innovations and they were seen to focus on enhancing existing products. Only $60 \%$ of NPD teams have their targets derived from company strategy (Barczak et al., 2009).

The direction for a company's performance management should be given by company mission statement and strategy (Haapasalo et al., 2006; Williams, 2008; King et al., 2010; Pinheiro de Lima et al., 2012. Strategic alignment is pointed out as the most important success factor for the development of business processes and performance management practices (Bai and Sarkis, 2013). According to Pinheiro de Lima et al. (2012) company's business processes and their performance management should be connected together as an integrated performance management framework. According to Falsey (1989) the mission statement defines the company, who it is, and what it does. The mission statement can be product, technology and customer oriented, and it defines the competitive advantage of the company (Falsey, 1989). The mission statement communicates values, pur- pose, identity, and business goals of the company and can be seen as the extension of the shorter vision statement (King et al., 2010). Mission statement is the declaration of an organisation's "reason for being" and it defines the position of the company in a value chain (David, 2009). According to Kinnunen et al. (2013), company's position in a value chain impacts the nature of its products and product portfolio. The ecosystem can be defined based on business models and relations of participating companies. According to David (1989) the mission statement should consist of nine preferred components: (1) Customer, (2) Product or Services, (3) Location, (4) Technology, (5) Concern of survival, (6) Philosophy, (7) Self-concept, (8) Concern for public image, (9) Concern for employees. Based on their study there are some similarities but also differences between high and low performing companies in the focus of nine components. Both high and low performers have equal focus on customers, products and services, and self-concept. Major differences are related to survival, the public image and employees which are more focused in high performing companies. The environmental and sustainability issues have been raised to the strategic level of company targets within the last decades. The sustainability issues are embedded in the eight mission statement component, social responsibility (David, 2009). According to Meinrenken et al. (2014) the current life cycle assessment (LCA) methodologies are yet to be applied for the entire product portfolios, however, they exist more on the level of individual products. For the purpose of improving LCA, Meinrenken et al. (2012) have studied the entire value 
chain and developed a method for collecting and analysing data in the context of carbon dioxide reduction scenarios. The challenge of measuring and setting environmental and sustain- ability targets for the product portfolios includes the lack of practical guidance documents in addition to the developments of ISO standards (Draucker et al., 2011).

According to Cooper et al. (1997), Barczak et al. (2009), Vähäniitty (2006), Leffingwell (2007), Weerd et al. (2006), Mikkola (2000), and Kamensky (2000) the key product portfolio performance focus areas can be summarised as follows: (1) the product portfolio strategic fit, (2) value maximisation, and (3) the balance of the product portfolio. Strategic fit ensures the consistency and alignment in the product portfolio according to company's strategic targets. Value maximisation as an objective includes sub-targets such as return-on-investment, profitability, success, and business value. Balancing the portfolio can be illustrated by terms and parameters such as time, risk, markets, and technologies. The PPM targets and KPIs are summarised in Table 1.

The literature findings on product portfolio management can be summarised by the following key statements:

- Company's performance targets should be described in the form of a mission statement (Williams, 2008; King et al., 2010; Falsey, 1989).

- Company's performance is linked to the rate of innovative new product and technology development (Barczak et al., 2009; Cooper et al., 2004; Cooper, 1996).

- The key performance areas in the product portfolio manage- ment are strategic fit, value maximisation and the balance of the product portfolio (Cooper, 2008; Cooper et al., 2001; O'Reilly and Tushman, 2004; Kamensky, 2000; Griffin, 1997; Cooper et al., 1999, 1997; Porter, 1996. Dickinson et al., 2001; Saaksvuori and Immonen, 2008).

The current literature on PPM covers well the NPD phase of the product life cycle, and related product portfolio management targets and KPIs. The focus and wording in the existing literature for PPM performance management is more often about "projects within NPD" than "products over life cycle". The later phases of the life cycle are not well covered, from the PPM perspective, by the existing PPM theory and earlier research. However, the need for product portfolio management and business processes alignment over life cycle phases are recognised in business process management theory (e.g. Bai and Sarkis, 2013). According to Saaksvuori and Immonen (2008), the typical life cycle phases include: (1) planning and introduction, (2) growth, (3) maturity and (4) decline. 
Table 1. PPM targets and KPIs (Cooper 2008, Cooper et al. 2001, O’Reilly et al. 2004, Kamensky 2000, Griffin 1997, Cooper et al. 1999, Cooper et al. 1997, Porter 1996, Dickinson et al. 2001, Saaksvuori and Immonen 2008).

\section{Strategic fit KPls}

- Product, development activity aligned with business strategy [Yes or No]?

- Value of strategic investment for R\&D and actual spending [Target $€$ / Actual $€$ ]?

- Number of resources in product development (R\&D, Sales, OPS, Services) [Target \# / Actual \#]?

- Strategic and spending alignment (where resources and funding are spent)

- Number of resources available for product development

\section{Value maximization KPIs}

- Market attractiveness by product: Market size, market growth \& future potential, Margins earned by others in this market, competitiveness and competition

- Solid commercial prospect, Size of financial opportunity)[Expected $€$ / LE $€ /$ Act $€$ ]

- Sales Turnover

- Product Cost, Cost of Goods Sold (COGS)

- Expected commercial value (ECV), Net Present Value (NPV)

- Gross Margin, Net Margin, Profitability, Net profit [€/reporting period)

- Internal Rate of Return (IRR),

- Number of High-value and return projects

Balanced and right size of the portfolio KPls

- Balance of resources: demand of resources for the product portfolio development and renewal / capacity of organization

- Balance of long term / short terms products or development activities, targeted vs actual

- Balance of high risk / low risk products or development projects, targeted vs actual

- Balance of technology, targeted vs actual (Technical feasibility, technical gap, familiarity of technology, technical track record, technical results of today - proof of concept)

- Size of the portfolio: Number of products, sales items, components, common modules $->$ \# of items on each product structure level

- Resource availability from Marketing \& Sales, R\&D, Technical, Operations, Services to develop and maintain the portfolio 


\section{Research process}

The research process is shown in Fig. 1. This research utilises qualitative and inductive research methods.

The existing literature on product portfolio management and PPM performance management was first reviewed to provide an adequate basis for the study. Based on the literature findings a questionnaire was formed to enable empirical analysis. The process management theory (Rummler and Brache, 1990; Bai and Sarkis, 2013; Slack et al., 2012) and approach were also utilised to support creating a comprehensive questionnaire, and to analyse whether the current practices apply process management methodologies. The empirical study consists of industrial interviews within ten case companies (Table 2) to clarify the current practices and challenges related to PPM targets and KPIs over life cycle. The interviews were recorded, extracted and transcribed to enable thorough analyses. The selected ten companies represent both large and global but also small and growing businesses such as Solutions, HW, SW, and Service products. The number of interviewees varied by the case company size. In larger companies, the interviews were conducted as several workshops including cross functional groups of man- agers, while in smaller companies only CEO (Chief Executive Officer), R\&D (Research and Development), or Product Management type of managers were interviewed.

The interview material was analysed thoroughly to identify currently used PPM targets and KPIs. Due to existing and practical wording used by most of the case companies the life cycle phases in questionnaire were simplified to the following four: new product development, Maintain, Warranty and Archive phases. An initial framework was created to enable managing product portfolio renewal over the product life cycle phases based on strategic, tactical and operational performance measures. Representatives of the ten case companies formed a focus group that was utilised to review and validate the proposed new PPM framework.

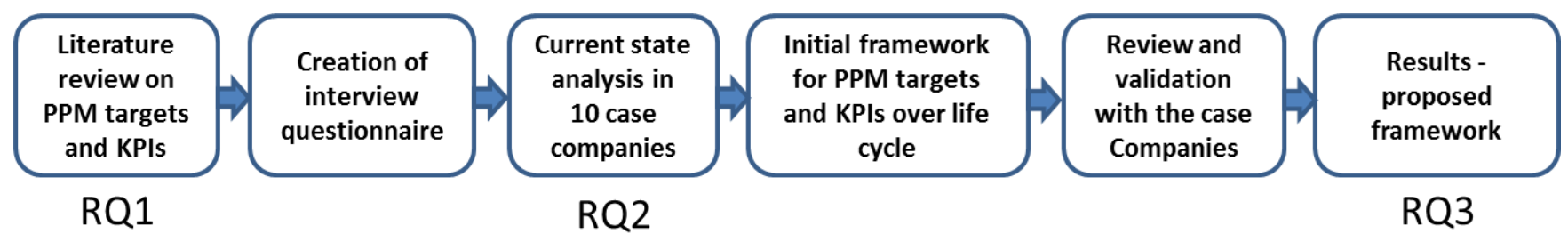

Figure 1. The research steps and process. 
Table 2. Characteristics of the case companies

\begin{tabular}{|c|c|c|c|}
\hline Case & Portfolio characteristics & Operational maturity & $\begin{array}{c}\text { \# of } \\
\text { intervie } \\
\text { wees }\end{array}$ \\
\hline
\end{tabular}

A $\quad \begin{aligned} & \text { Small portfolio of HW products and emerging } \\ & \text { related service business. Retailers and business } \\ & \text { customers. }\end{aligned}$
B $\quad \begin{aligned} & \text { A large portfolio of solutions, HW, SW and } \\ & \text { Services products under strategic renewal. Global } \\ & \text { business customers. }\end{aligned}$
C $\quad \begin{aligned} & \text { Small innovative portfolio of SW products. } \\ & \text { Consumer customers via business partners }\end{aligned}$
D $\quad \begin{aligned} & \text { Global portfolio of HW, SW and Services products. } \\ & \text { Business customers. }\end{aligned}$

New national rival in mature business

Experienced global innovator in both mature and new business with strong R\&D investments.

Growing international presence in new growth business

A global supplier with long history in the business. Both organic growth and by business acquisitions

E A new service oriented product portfolio is being established. Regional consumer customers.

New innovator in a growth market

Experienced growing company in mature global business business customers.

G Medium size HW product portfolio under strategic renewal. Global, regional and local business customers.

Experienced global leader in declining business, new growth and business potential via portfolio renewal

H Attractive traditional HW product portfolio for consumers with new additional services and HW accessory type of products.

I Global portfolio of HW, SW, Services and Both mature and new innovative HW products with accessories.

Global supplier in mature business Solutions. Global, regional and local business customers.

J Global portfolio of HW and Services products. Global, regional and local business customers.

Both mature and new innovative HW and 4 Services products in mature global business. 


\section{Results and analysis}

\subsection{The current state of the case companies in PPM performance management}

Product portfolio management and related performance management are seen as common challenges in the case companies. PPM is viewed nearly non-existent topic of management attention, not only from the strategic target setting and performance management viewpoint, but also from the points of related processes and tools, and the ownership and governance model.

Overall, the visibility over the product portfolio as a whole is seen not to be consistent due to many different product views and missing reporting capabilities. The growing size and the proliferation of the product portfolio are experienced among the most common challenges in the case companies. The total revenue share per product decreases, and products and their technical relations to each other are becoming complicated to maintain, resulting in cannibalisation within product families, in negative product business cases, and obsolete materials. The focus of life cycle management has been more on single components, modules, units and products than on the entire product portfolio. The targeted durations of product life cycles are seen not to be planned in original business plans for new products. Companies have simply followed their customers' behaviour and their requirements for product development, and less attention has been paid on product portfolio management over life cycle. Explosion of the product portfolio is seen to happen in most of the case companies due to the lack of clear PPM concept and related performance management over product life cycle. More new products are generated to product portfolio by NPD, mergers and acquisitions, faster than companies are able to replace and remove. The explosion of the product portfolio can be illustrated in Figure 2.

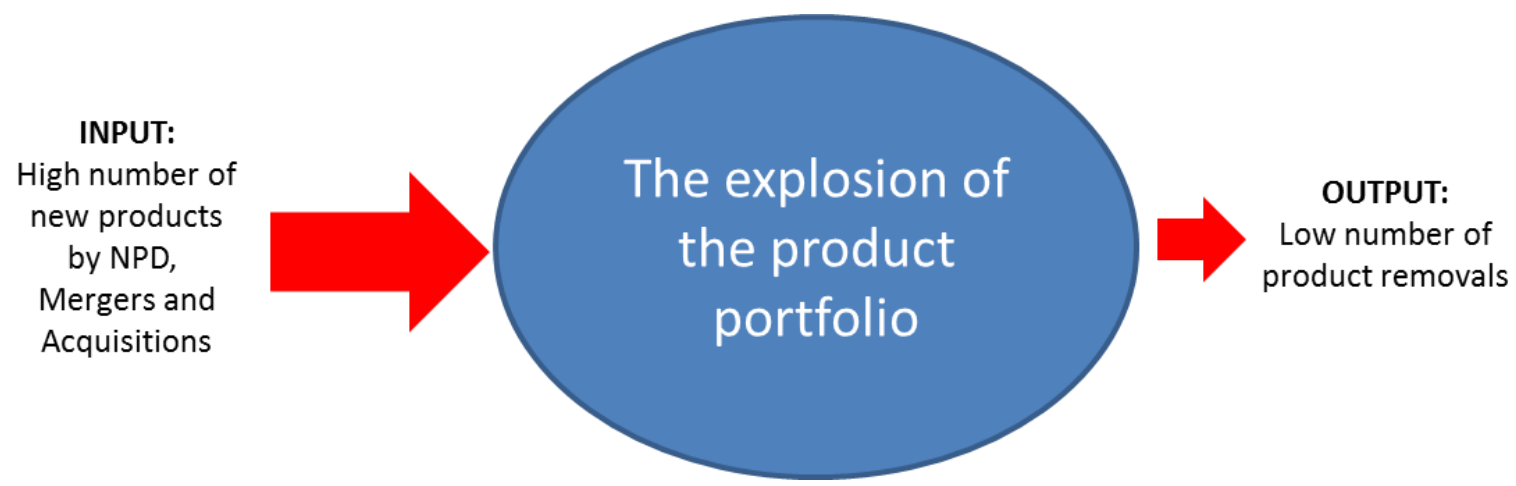

Figure 2. The explosion of the product portfolio as a generic challenge in studied case companies.

Surprisingly, the PPM targets and KPIs are not experienced as known concepts of PPM related performance management. Some PPM related KPIs are used, such as sales and delivery volume, product cost information and high level profitability reporting. The financial targets are typically set at the company level only, and in a few cases at the level of sub-portfolios. According to the interviewees, products are sold as components of bigger projects, thus the profitability of the products cannot be measured. In a relation to the portfolio balance, the case companies are targeting to reduce their product portfolios and to clean-up the related product data. The companies pay attention to the number of items on different levels of the product structure, but related targets and KPIs are not set in most of the cases. The lack of the profitability KPIs at the portfolio, sub-portfolio and product levels are seen to potentially be one of the most critical challenges in the case companies.

The usability of PPM as a concept and a tool for strategy implementation and for performance management, are not consistently understood and utilised by the case companies. The PPM targets and KPIs are not in place as known performance management topics, even though some related metrics exist. In addition, from the viewpoint of different functions and business processes there is a potential conflict of interest in PPM targets 
and KPIs.

\subsection{Framework for product portfolio management targets and KPIs over life cycle}

The idea of the continuous renewal of the product portfolio assumes the frequent horizontal flow of products from NPD phase to later phases of the life cycle. Also, the removal of products should happen as well to avoid the explosion of the product portfolio. This type of end-to-end approach requires a new type of framework in PPM to connect the decision making of the new and existing products together. New product decisions should include the decision to move one or more older products further in their life cycle until the final removal of the old products in order to renew and maximise the value of the product portfolio within all life cycle phases.

The new performance management framework should respond to company's strategic targets and be based on the identified performance management focus areas of the PPM. The developed framework for PPM targets and KPIs over life cycle can be founded on four main cornerstones:

1) The nine components of mission statement

2) Three PPM performance management focus areas

3) The idea of horizontal sub portfolios over life cycle

4) Company's performance management dashboard, including the PPM targets and KPIs

The recommendation for the case companies is to first describe their strategic targets by creating the nine components of the mission statement. During the second phase, the three areas of PPM targets and KPIs are to be set for each component of the mission statement. By this approach the relation between the mission statement and the PPM targets and KPIs can be ensured. The relation of the first two cornerstones is described in Table 3 as a matrix of the mission statement and the PPM performance management focus areas.

As the third cornerstone the horizontal sub portfolios should be created based on four life cycle phases: NPD, Maintain, Warranty and archive:

- NPD portfolio: focus on product concept development, design and engineering.

- Maintain portfolio: focus on product sales and delivery ramp up, volume phase management and ramp down of product sales and deliveries.

- Warranty portfolio: focus on spare part and case service businesses.

- Archive portfolio: focus on legally required product data archive for removed products

Table 3. The matrix of the mission statement and the PPM performance management focus areas.

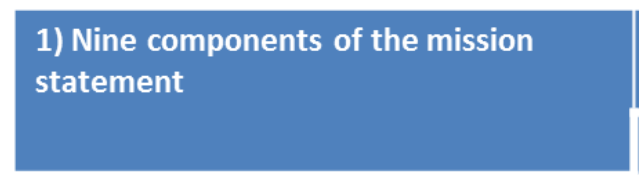

1. Market Segments

2. Customers

3. Products (HW, SW, Services, Docs)

4. Technology

5. Economic success

6. Competitive Advantage

7. Values

8. Public image and social responsibility

9. Employees
2) PPM focus areas in target setting and performance management

\begin{tabular}{|l|l|l}
\hline Strategic FIT & Value maximization & Portfolio Balance
\end{tabular}

\begin{tabular}{|c|c|c|}
\hline$x$ & $x$ & $x$ \\
\hline$x$ & $x$ & $x$ \\
\hline$x$ & $x$ & $x$ \\
\hline$x$ & $x$ & $x$ \\
\hline$x$ & $x$ & $x$ \\
\hline$x$ & $x$ & $x$ \\
\hline
\end{tabular}


The above phases of the product portfolio life cycle are presented in Figure 3. The nature of business requirements and related activities differ within the four life cycle phases thus the PPM targets and KPIs need to be further adjusted for each horizontal sub-portfolio. For the NPD phase, the targets and KPIs are more strategic and long term, while for the rest of the phases they are more operational and dynamic based on the changes in the business environment. The common target among the horizontal portfolios is the continuous renewal and the flow of products from NPD portfolio to Maintain, Warranty and Archive portfolios based on the related PPM targets and KPIs. The criteria and related gates between the horizontal portfolios are crucial to define to enable the frequent flow of products and the product portfolio renewal. The main focus of horizontal sub-portfolios are described in Figure 4. The fourth cornerstone in the framework is company's performance management "dashboard", connecting PPM performance management with the business processes' strategic targets and KPIs. PPM impacts the performance of business processes by frequently renewing the product portfolio, and thus enabling the business processes to create, sell, deliver and care only the group of products that are creating the highest strategic fit, maximized value and the balance for the company and its stakeholders. The idea of the company's "dashboard" is described in Figure 5.

Product portfolio renewal requires strategic targets and KPIs over life cycle connecting the PPM analysis and decision making of new and existing products. Ideally, product portfolio renewal would occur in balance and synchrony with new product intro- ductions and old products ramp downs. The strategy, vision and mission statements are the highest level of documentation that set business goals for a company. Any other strategy documents should be seen more as execution plan types of documents that describe how to implement and follow up the strategy execution.

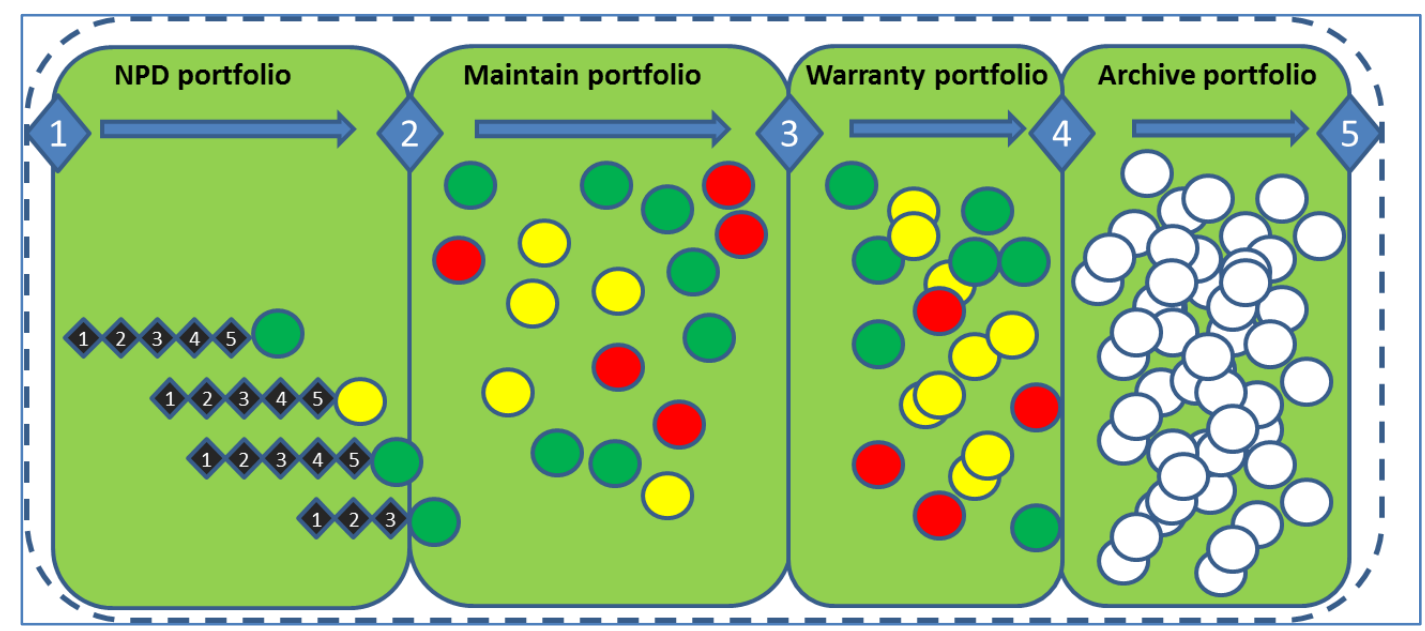

Figure 3. The third cornerstone: horizontal sub product portfolios. 


\section{1) The NPD product portfolio}

- Define, develop and ramp up new products and versions to renew the portfolio for the future according to agreed targets and performance metrics of strategic fit, max value and balance.

2) The Maintain product portfolio

- Run the business based on existing streamlined Maintain portfolio.

- $\quad$ Replace and ramp down agreed existing products by the developed new products according to agreed targets and performance metrics of strategic fit, max value and balance.

3) The Warranty product portfolio

- Run the care business based on streamlined Warranty portfolio according to agreed customer contracts and legal requirements.

- Ramp down the spare parts and services according to agreed targets and performance metrics of strategic fit, max value and balance and which are contractually, legally possible.

4) The Archive product portfolio

- Archive the item information based on legal requirements

- Clean up and remove the items according older than required legal standards ( 10 years data archive requirement)

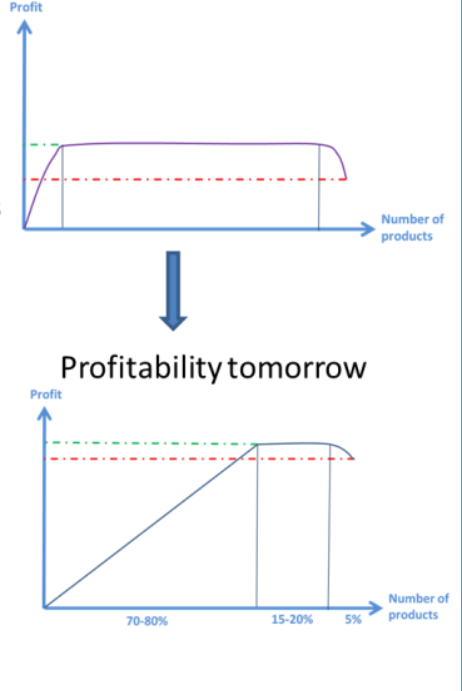

Figure 4. The main focus of horizontal sub portfolios.

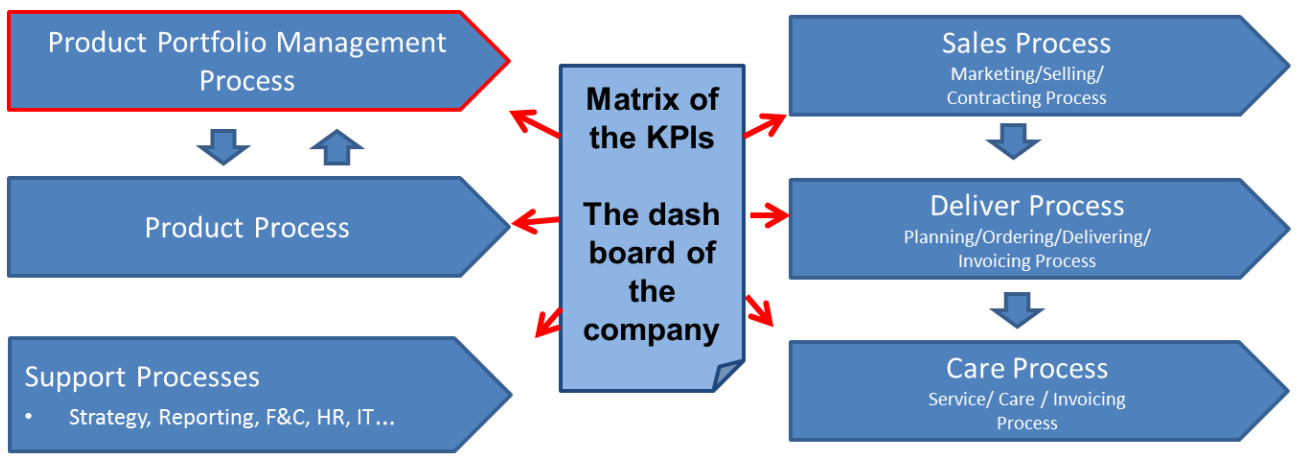

Figure 5. The fourth cornerstone: company's dashboard including PPM targets and KPIs over life cycle. 


\section{Discussion and implications}

This study proposes a new performance management frame- work for PPM over life cycle including the creation of strategic PPM targets as a matrix of mission statement and PPM focus areas over horizontal product portfolios. In addition, the "company dashboard" is proposed for synchronising and aligning the PPM targets with the targets of the business processes.

The managerial implications of this study include the potential new PPM performance management framework as a precondition for improving PPM practices to avoid the explosion of the product portfolio. The research is relevant especially for the case companies facing growing product portfolios in infrastructure business. The disadvantage of the growing product portfolios is the most significant in business situations where the increased number of products merely creates additional costs without additional sales revenues. Stable or even decreasing total sales revenues with increased number of products in portfolios leads to decreased sales and profitability per product. The explosion of the HW and SW product portfolios are particularly challenging in the infra- structure type of Business-To-Business (B2B) environment where the existing products can be used tens of years in parallel with new products. In consumer industry the new products typically replace the older ones by simultaneous new product ramp ups and old product ramp downs. The pressures to allow the growth of the product portfolios are higher in companies operating in global markets than in companies present only in local markets. The product portfolio management over life cycle widens the decision making over life cycle by connecting the decisions for new product development and existing product ramp downs. The findings can enhance business managers' understanding on the PPM as an entity that has a role in managing products and portfolios based on strategic and financial targets over product life cycles to ensure sustainable renewal of the entire portfolio according to four planned horizontal sub-portfolios. Hence, the proposed framework acknowledges the different nature of business requirements and activities typical for each horizontal subportfolio. The proposed dashboard can aid in enhancing management focus on the connection between company strategy and the targets of PPM, and business process over life cycle. The performance management dashboard can be used as a follow up tool in strategy implementation by synchronising the targets of PPM and business processes and minimising the risk for confusion on the strategic direction.

This study contributes to the existing literature by introducing a framework for PPM performance management over life cycle, one that takes an end-to-end approach and acknowledges the challenges faced by industrial actors. The framework particularly promotes continuous product portfolio renewal. This is in line with those studies that emphasise the importance of avoiding unnecessary portfolio growth (e.g. Droge et al., 2012; Wan et al., 2012; Cooper and Griffiths, 1994; Randall and Ulrich, 2001; Thonemann and Bradley, 2002; Wan et al., 2012). Product intro- ductions should be followed by rampdowns of previous product generations to avoid portfolio explosion especially when the total sales turnover is not increased by the added new products.

This study emphasises the importance of mission statement as a context for company strategy and for guiding product portfolio management by creating a link between them. This supports studies highlighting the importance of strategy focus (e.g. Cooper, 1996; Barczak et al., 2009; Haapasalo et al., 2006; Williams, 2008; King et al., 2010; Bai and Sarkis, 2013; Pinheirode Lima et al., 2012). The mission statement defines the company, 
an important aspect that this study recognises by utilising mission statement as one of the cornerstones for the introduced framework. This is consistent with studies emphasising the importance of describing company's performance targets in the form of a mission statement (Williams, 2008; King et al., 2010; Falsey, 1989).

Introducing the framework provides contribution to literature that has recognised the need for product portfolio management and business processes alignment over life cycle phases (e.g. Bai and Sarkis, 2013), particularly by attempting to cover also the latter phases. Previous studies (Cooper et al., 2004; Barczak et al., 2009; Griffin, 1997; Leffingwell, 2007) mostly focus on the new product development phase of the product portfolio, more addressing projects within NPD rather than product over life cycle. This study emphasises the importance of acknowledging the change in the nature of business requirements along life cycle phases by adjusting PPM targets and KPIs horizontally to aid sustainable and continuous portfolio renewal. These adjustment needs are addressed in the framework by bringing forward the idea of horizontal sub-portfolios over life cycle as one of the cornerstones.

The introduced framework using nine components of mission statement and three PPM performance management focus areas of strategic fit, value maximisation, and portfolio balance as the cornerstones supports the previous research on their importance (Cooper, 2008; Cooper et al., 2001; O'Reilly and Tushman, 2004; Kamensky, 2000; Griffin, 1997; Porter, 1996. Dickinson et al., 2001; Saaksvuori and Immonen, 2008). The proposed framework also emphasises the role of company's performance management dashboard as an important link between PPM performance management with strategic targets and business process KPIs.

The first two cornerstones (1) nine components of mission statement and (2) three PPM performance management focus area can be seen as proven recommendations based on the earlier studies and literature. The last two cornerstones (3) idea of the horizontal product portfolios and (4) the performance management dashboard can be seen as conjecture type of recommendations for the case companies and in general. The proposed new PPM framework is yet to be fully implemented by the case companies. However, the created PPM framework has been discussed and evaluated in a common focus group meeting with the case companies. 


\section{Conclusions}

The trend towards more complex and wider product offering has resulted in accelerated introductions of new products and product variants. More new products are introduced than products are removed from the portfolio. This has led to the explosion of product portfolios in a negative sense when the sales revenues and market shares can no longer be increased accordingly.

This study analyses the PPM targets and KPIs over life cycle and attempts to develop a PPM performance management framework that would enable managing sustainable product portfolio renewal over the entire product life cycle based on strategic, tactical and operational performance measures.

The current PPM performance management literature mainly focuses on the NPD phase of product life cycle. According to the literature findings, NPD projects are evaluated based on three PPM performance management focus areas: strategic fit, maximised value and portfolio balance. The rest of the "horizontal" life cycle phases are not covered deeply enough from the PPM performance management perspective by the existing research.

PPM performance management challenges were identified and viewed to be very common in the analysed case companies. Companies following customers' requirements for product development have resulted in less attention being paid on product portfolio management over life cycle. The visibility over the entire product portfolio has often been limited to single products, different product views and specific life cycle phases depending on the stakeholder. The explosion of product portfolios have occurred in most of the case companies due to the lack of clear PPM strategic targets, potential conflicts of interest in PPM and deficiencies in follow up over life cycle. Only a few of the currently used performance measures can be directly linked to PPM performance management. These include the number of products, and sales and delivery volumes; however related numerical targets have been not set in most of the cases at the portfolio level. The financial targets are typically set at the company level only, and in a few cases at the level of sub portfolios. The lack of profitability KPIs at the portfolio, sub-portfolio and product levels are seen to cause critical challenges in case companies A created framework for PPM performance management over life cycle includes four cornerstones: the nine components of a mission statement, three performance management focus areas of the PPM, the horizontal sub portfolios, and a performance management dashboard. This type of performance management framework may have the potential to enable effective and strategic sustainable product portfolio renewal over life cycle.

The limitations of this study include analysing a limited number of companies with a low maturity level of PPM performance management practices. There was also a question if the "Innovation portfolio", the previous life cycle before NPD portfolio, should be taken into scope. It was intentionally excluded due to the already wide end-to-end life cycle scope, from NPD phase to the final archive and removal phases.

Fundamental questions were raised during the analysis, ones that might prove worth further researcher, including: (a) How much do the PPM targets and KPIs differ for the horizontal sub portfolios, (b) Can product portfolios be visualised vertically to increase the understanding on the related PPM targets and KPIs at product structure levels? 


\section{References}

Bai, C. and Sarkis, J., 2013. A grey-based DEMATEL model for evaluating business process management critical success factors, International Journal of Production Economics, 146 (1), 281-292.

Balachandra, R., 1997. Factors for success in R\&D projects and new product innovation: A contextual framework, IEEE Transactions on Engineering Management, 44 (3), 276-287.

Barczak, G., Griffin, A., Kahn, B., 2009. PERSPECTIVE: Trends and Drivers of Success in NPD, Practices: Results of the 2003 PDMA Best Practices Study, Product Innovation Management, 26 (1), 3-23.

Cooper, R., 1996. Overhauling the New Product Process, Industrial Marketing Management, 25 (6), 465-482.

Cooper, R., 2008. Perspective: The Stage-Gate, Idea-to-Launch Process - Update, What's New, and NexGen Systems, The Journal of Product Innovation Management, 25 (3), 213-232.

Cooper, J. and Griffiths, J., 1994. Managing Variety in Automotive Logistics With the Rule of Three, International Journal of Logistics Management, 5 (2), 29 -40.

Cooper, R.G., Edgett, S.J., and Kleinschmidt, E.J., 2004. Benchmarking Best NPD Practices-II, Research Technology Management, Industrial Research Institute Inc, 50-59.

Cooper, R.G., Edgett, SJ., and Kleinschmidt, EJ., 2001. Portfolio Management for new product development: Results of an industry practices study, $R \& D$ management, 31 (4), 361-380.

Cooper, R.G., Edgett, S.J., and Kleinschmidt, E.J., 1999. New product portfolio management: Practices and performance, Journal of Product Innovation Management, 16 (4), 333-351.

Cooper, R.G., Edgett, SJ., and Kleinschmidt, EJ.,1997. Portfolio management in new product development: Lessons from the Leaders-I, Research Technology Management, 40 (5), 16-28.

David, F. R., 1989. How companies define their mission, Long Range Planning, 22 (1), 90-97.

David, F.R., 2009. Strategic Management: Concepts and Cases, Twelfth edition, Upper Saddle River, NJ: Pearson.

den Hartog, E-J., 2012. Reducing complexity at Procter \& Gamble -complexity approach towards product portfolio management, Master Thesis in Industrial Engineering \& Management, University of Twente.

Dickinson, M.W., Thornton, A.C., Graves, S., 2001. Technology portfolio management: Optimizing interdependent projects over multiple time periods, IEEE Transactions on Engineering Management, 48 (4), 518-527.

Droge, C., Vickery, S.K., and Jacobs, M.A., 2012. Does supply chain integration mediate the relationships between product/process strategy and service performance? An empirical study, International Journal of Production Economics, 137 (2), 250-262.

Falsey, T. A., 1989. Corporate philosophies and mission statements: A survey and guide for corporate communicators and management, Westport, CT:Greenwood, 169.

Griffin, A., 1997. PDMA research on the new product development practices: Updating trends and benchmarking practices, Journal of Product Innovation Management, 14 (6), 429-458.

Gunasekaran, A., Patel, C., and McGaughey, R.E., 2004. A framework for supply chain performance measurement, International Journal of Production Economics, 87 (3), 333-347.

Haapasalo, H., Ingalsuo, K., and Lenkkeri, T., 2006. Linking Strategy into Operational Management - A Survey of BSC Implementation in Finnish Energy Sector. Benchmarking: An International Journal, 13 (6), 701-717.

Hayes R.H., Pisano G.P., Upton D.M., and Wheelwright S.C., 2005. Operations, Strategy, and Technology: Pursuing the Competitive Edge, John Wiley \& Sons, Inc., 369.

Hänninen, K., Kinnunen, T., Haapasalo, H. and Muhos, M. (2013) 'Rapid productisation challenges and preconditions', International Journal of Product Lifecycle Management, 6(3), 211-227.

Kamensky, M., 2000. Strateginen johtaminen, Gummerus Kirjapaino Oy, Jyväskylä.

Kaplan, R.S, and Norton, D.P, 2001. The strategy-focused organization, Soundview Executive 
Book Summaries, Concordville, Pennsylvania.

King, D.L., Case, C.J., and Premo, P.M., 2010. Current Misson Statement Emphasis: Be Ethical and Go Global, Academy of Strategic Management Journal, 9 (2), 71-87.

Kinnunen, T., Sahlman, K., Harkonen, J., and Haapasalo, H., 2013. Business ecosystem perspective to new product development, International Journal of business development and research, 1 (1), 5-20.

Kropsu-Vehkapera, H., Haapasalo, H., 2011. Defining product data views for different stakeholders, Journal of Computer Information Systems, 52 (2), 61-72.

Langenberg, K.U., Seifert, R.w., and Tancrez, J-S., 2012. Aligning supply chain portfolios with product portfolios, International Journal of Production Economics, 135 (1), 500-513.

Leffingwell, D., 2007. Scaling Software Agility: Best Practices for Large Enterprises. Boston, MA, Addison-Wesley.

Lynn, G.S., Abel, K.D., Valentine, W.S. and Wright, R.C.,1999. Key factors in increasing speed to market and improving new products success rates, Industrial Marketing Management, 28 (4), 319-326.

Mikkola, J.H., 2000. Portfolio management of R\&D projects: implications for innovation management, Technovation, 21 (7), 423-435.

O'Reilly III, C.A., and Tushman M. L., 2004. The Ambidextrous Organization, Harward Business Review, 82 (4), 74-81.

Orfi, N., Terpenny, J., and Asli, S.S., 2011. Harnessing product complexity: Step 1 - Establishing product complexity dimensions and indicators, The Engineering Economist, 56 (1), 59-79.

Pekuri, A., Haapasalo, H., and Herrala, M., 2011. Productivity and Performance Management Managerial Practices in the Construction Industry, International Journal of Performance Measurement, 1 (1), 39-58.

Pinheiro de Lima, E., Gouvea da Costa, S.E., and Angelis, J.J., 2012. Performance Measurement Systems: A consensual analysis of their roles, International Journals of Production Economics, 146 (2), 524-542.

Poolton, J., and Barclay, I., 1998. New product development from past research to future applications, Industrial Marketing Management, 27 (3), 197-212.

Porter, M. E., 1996. What is strategy, Harward Business Review, 74 (6), 61-78.

Randall, T., and Ulrich, K., 2001. Product variety, supply chain structure, and firm performance: analysis of the US bicycle industry, Management Science, 47 (12), 1588-1604.

Rummler, G.A., and Brache, A. P., 1990. Improving Performance. How to manage the white space on the organization chart, Jossey-Bass Inc., Publishers, San Francisco, California.

Saaksvuori, A., and Immonen, A., 2008. Product Lifecycle Management, Sringer-Verlag Berlin Heidelberg, 253p.

Salvador, F., Forza, C., and Rungtusanatham, M., 2002. Modularity, product variety, production volume, and component sourcing: theorizing beyond generic prescriptions, Journal of Operations Management, 20 (5), 549-575.

Slack, N., Brandon-Jones, A., and Betts, A., 2012. Principles and Practices for Strategic Impact, Operations and Process Management, Pearson Education Limited, Harlow, England, 576p.

Thonemann, U.W. \& Bradley, J.R., 2002. The effect of product variety on supply-chain performance, European Journal of Operational Research, 143 (3), 548-569.

Vähäniitty, J., 2006. Do small software companies need portfolio management?, Licenciate thesis, Helsinki University of Technology, Department of computer science and engineering.

Wan, X., Evers, P.T. \& Dresner, M.E., 2012. Too much of a good thing: The impact of product variety on operations and sales performance, Journal of Operations Management, 30 (4), 316324.

Weerd, I., Brinkkemper, S., Nieuwenhuis, R., Versendaal, J., and Bijlsma, L., 2006. Towards a Reference Framework for Software Product Management, Requirement Engineering, $14^{\text {th }}$ IEEE 
International Requirements Engineering Conference in Minneapolis US, 319-322.

Williams, L.S., 2008. The Misson Statement. A Corporate Reporting Tool with a Past, Present, and Future, Journal of Business Communication, 45 (2), 94-119. 